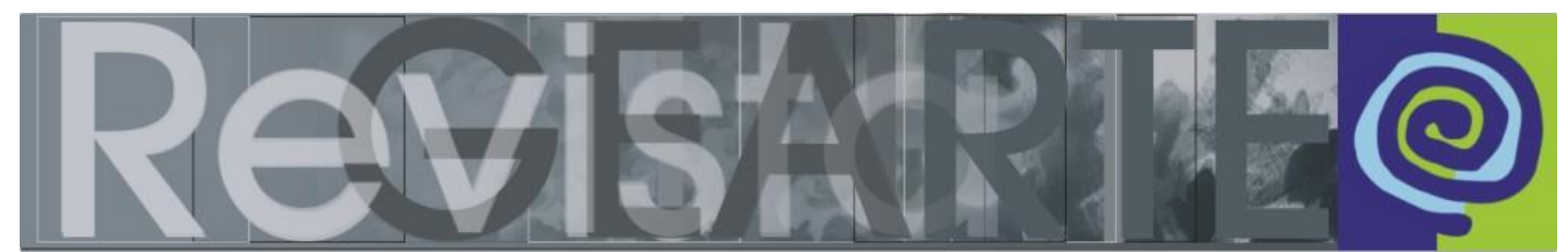

ISSN 2357-9854 | e-ISSN 2596-3198 (online)

\title{
Mapeamento dos cursos de Pedagogia e do estado da arte sobre indicadores da Arte na Pedagogia
}

\author{
Ana Luiza Ruschel Nunes \\ (Universidade Estadual de Ponta Grossa - UEPG, Ponta Grossa/PR, Brasil) \\ Andréia Bulaty \\ (Universidade Estadual do Paraná - UNESPAR, União da Vitória/PR, Brasil)
}

\begin{abstract}
RESUMO - Mapeamento dos cursos de Pedagogia e do estado da arte sobre indicadores da Arte na Pedagogia - O objetivo do texto é mapear, descrever e sistematizar as pesquisas brasileiras que têm como foco de estudo a Arte na Pedagogia, pesquisando e mapeando os cursos de licenciatura em Pedagogia no Brasil e do estado da arte e do conhecimento das produções acadêmicas sobre a arte na Pedagogia, no período de 2006 a 2018, com a problemática investigada: Qual é o estado da arte e do conhecimento das produções da pesquisa acadêmicas sobre e da Arte na Pedagogia? A pesquisa é qualitativa delineada pela metodologia do Estado da Arte e do Conhecimento em que foi encontrado 43 produções científicas no período de 12 anos. O Brasil em 2018, tinha 2752 cursos de Pedagogia, destes 1333 cursos presenciais e $1389 \mathrm{EaD}$, sendo que no Paraná tem 183 cursos Pedagogia.
\end{abstract}

\section{PALAVRAS-CHAVE}

Curso de Pedagogia. Arte. Conhecimento.

\begin{abstract}
Mapping of Pedagogy courses and the state of the art on indicators of Art in Pedagogy - The aim of the text is to map, describe and systematize Brazilian research that focuses on Art in Pedagogy, researching and mapping the degree courses in Pedagogy in Brazil and the state of the art and knowledge of academic productions about Art in Pedagogy, from 2006 to 2018, with the investigated issue: What is the state of the art and knowledge of academic research productions about and Art in Pedagogy? The research is qualitative, outlined by the State of the Art and knowledge methodology, in which 43 scientific productions were found in a 12 year period. In 2018, Brazil had 2752 Pedagogy courses, of which 1333 on-site courses and $1389 \mathrm{EaD}$, while Paraná has 183 Pedagogy courses.
\end{abstract}

KEYWORDS

Pedagogy course. Art. Knowledge.

RESUMEN - Mapeo de cursos de Pedagogía y el estado del arte sobre indicadores de Arte en Pedagogía - El objetivo del texto es mapear, describir y sistematizar la investigación brasileña que se enfoca en Arte em Pedagogía, investigando y mapeando los grados en Pedagogía en Brasil y el estado del arte y conocimiento de las producciones académicas sobre arte en Pedagogía, de 2006 a 2018, con el tema investigado: Cuál es el estado del arte y conocimiento de las producciones de investigación académica sobre y Arte en Pedagogía? La investigación es cualitativa, perfilada por la metodología Estado del Arte y el Conocimiento en la que se encontraron 43 producciones científicas en un período de 12 años. En 2018, Brasil tuvo 2752 cursos de Pedagogía, de los cuales 1333 cursos presenciales y $1389 \mathrm{EaD}$, mientras que Paraná tiene 183 cursos de Pedagogía.

PALABRAS CLAVE

Curso de Pedagogía. Arte. Conocimiento. 


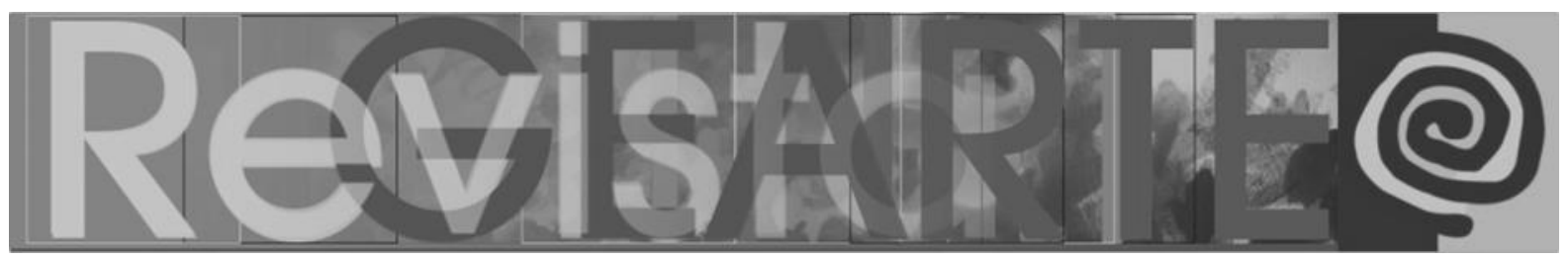

\section{Introdução}

Este texto apresenta resultados relativos à primeira fase do projeto de pesquisa de âmbito nacional intitulado Mapeamento dos Cursos de Pedagogia e Estado da Arte da Pesquisa Brasileira sobre e da Arte na Pedagogia. Projeto vinculado ao Grupo de Estudos e Pesquisas em Artes Visuais, Educação e Cultura (GEPAVEC/UEPG-CNPq), que tem por objetivo mapear, descrever e sistematizar as pesquisas brasileiras que têm como foco de estudo a Arte na Pedagogia, pesquisando e mapeando os cursos de licenciatura em Pedagogia no Brasil e do estado da arte e do conhecimento das produções acadêmicas sobre a Arte na Pedagogia, no período de 2006 a 2018.

Nessa direção, o artigo dá visibilidade para o mapeamento dos cursos de Pedagogia presenciais e EaD no Brasil, que são cursos que têm como eixo e perfil principal a formação de professores para a educação infantil e os primeiros anos do ensino fundamental I e são, em especial, voltados para a temática Currículo e Arte na Pedagogia. Apresentamos, também, de forma mais específica, um recorte da totalidade da materialidade objetiva do estado da arte e do conhecimento das produções acadêmicas sobre e da Arte na Pedagogia. Ele é apresentado em uma processualidade de pesquisa, ainda não conclusiva em sua totalidade, cuja cartografia apresenta diferentes regiões do Brasil dos cursos de Licenciatura em Pedagogia.

No primeiro momento, realizamos um inventário sobre os cursos de Pedagogia no Brasil e no estado do Paraná. À nível estadual, para compreender a realidade em que atuamos e realizar um estudo e uma pesquisa do estado da arte e do conhecimento sobre as produções científicas, de forma mais aprofundada, na área de Arte e Pedagogia.

Se considerou importante conhecer e compreender a inserção da Arte na Pedagogia em suas múltiplas dimensões históricas de formação e ou semiformação de professores em arte nos cursos de pedagogia do Brasil. Nesse 


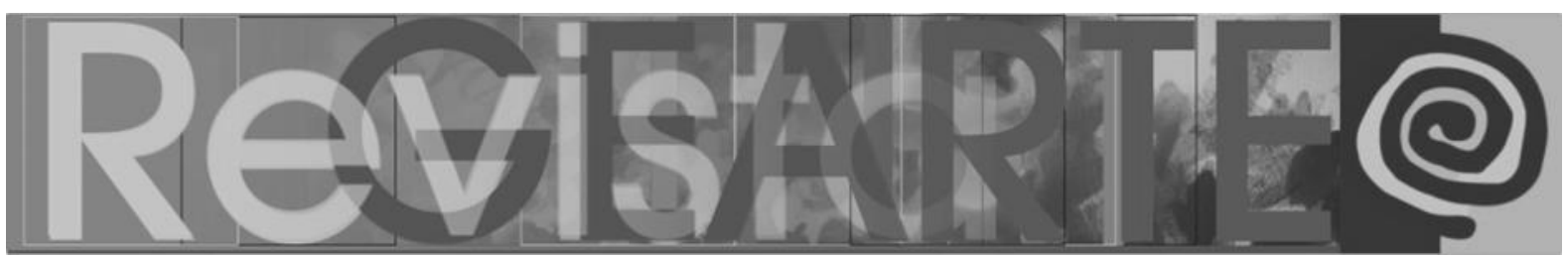

sentido, o recorte de pesquisa, apresentado neste artigo, expõe um mapeamento dos cursos de Licenciatura em Pedagogia tanto presenciais, quanto na modalidade EaD. Também, é exposta, aqui, parte do estado da arte e do conhecimento da Arte na Pedagogia.

A pesquisa qualitativa é delineada por uma metodologia do estado da arte e do conhecimento. A presente pesquisa, do tipo Estado da Arte, segundo André (2006), é caracterizada como de natureza documental-bibliográfica. Além disso, ela é caracterizada por Ferreira (2002) como uma pesquisa de caráter bibliográfico, que propõe mapear e discutir produções acadêmicas em algum campo de conhecimento, na tentativa de achar resposta sobre os aspectos e dimensões, no nosso caso, do mapeamento dos cursos de Pedagogia e do estado da Arte e do conhecimento na pedagogia. Assim, primeiro foi definido o tema e os objetivos a partir da indagação: quais são os cursos de Pedagogia presencial e EaD no Brasil e, mais especificamente, no estado do Paraná? Qual é o estado da arte e do conhecimento das produções da pesquisa acadêmicas sobre e da Arte na Pedagogia?

Assim, objetiva-se mapear, descrever e sistematizar as pesquisas nas produções acadêmicas no campo de conhecimento da Arte na Pedagogia, em busca de melhor entender e compreender os aspectos, as dimensões e as tendências sobre a Arte na Pedagogia. Assim, iniciaremos a discussão pelo encaminhamento e pela organização da pesquisa com o mapeamento e com o estado da arte e do conhecimento sobre e da temática da pesquisa.

\section{Síntese Conceitual sobre Mapeamento e Estado da Arte da Pesquisa}

O termo "mapeamento" diferencia-se do "estado da arte da pesquisa", pois o primeiro se refere à identificação, à localização e à descrição dos cursos de licenciatura em pedagogia criados e implantados num determinado tempo, espaço e campo de conhecimento. O mapeamento se preocupa mais com os aspectos descritivos de um campo de estudo. No nosso caso, o foco maior é mapear, os 


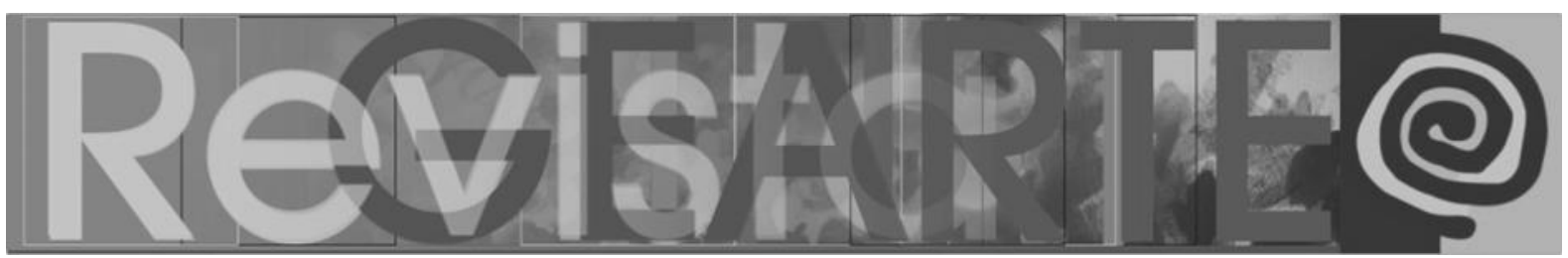

cursos de Licenciatura em Pedagogia no Brasil e o estado da arte na pesquisa acadêmica, sobre a Arte na Pedagogia. Pode-se sintetizar que, na nossa compreensão, o mapeamento da pesquisa como um processo sistemático de levantamento e descrição de informações acerca dos cursos são produzidas sobre um campo específico de estudo, abrangendo um determinado espaço (lugar) e período de tempo. Espaço, muitas vezes, na presente pesquisa, trilhado por vários lugares, capturados como localização em espaços que exigiram captura, como nos diz Panofsky (2007), o que remete fortemente a escavar. Aqui, apropriamo-nos desse termo em relação a escavar o estado da arte e do conhecimento, quando submetemos o material a uma análise arqueológica racional da pesquisa das produções acadêmicas da Arte na Pedagogia de certo ponto tão meticulosamente exata, ampla como uma pesquisa, cujo material foi buscado detalhadamente exato e extenso, daí a denominação de escavar de forma profunda não por uma síntese intuitiva, e sim escavar num aprofundar meticulosamente o objeto de pesquisa historicamente, que Panofsky (2007) se refere como uma arqueologia racional. Essas informações dizem respeito aos aspectos físicos dessa produção (descrevendo onde, quando e qual o tempo de criação, bem como quantos estudos foram produzidos em movimento, quais seus objetivos, suas metodologias, seus problemas de pesquisa e seus resultados - ainda em processo de maior aprofundamento -, ainda aprofundando em análise referente ao período.

Tomamos, como campo de estudo, a Arte na Pedagogia e, posterior, o professor pedagogo que ensina Arte na Pedagogia, cobrindo um período que vai de 2006 a 2018, de modo a compreender os últimos doze anos. Além disso, este tipo de produção intelectual do estado da arte - da Arte na Pedagogia- representa um esforço que se situa na fronteira do conhecimento e que traz o processo de produção de conhecimento sobre o ensino da Arte na Pedagogia, assim como a formação do pedagogo no campo do conhecimento em Arte. Isso revela, ainda que parcial, tendências teóricas dessa produção. Embora os resultados do mapeamento dos cursos de Pedagogia fazem parte da pesquisa, esses aspectos, como já dissemos, são geralmente atribuídos aos estudos do estado da arte da 


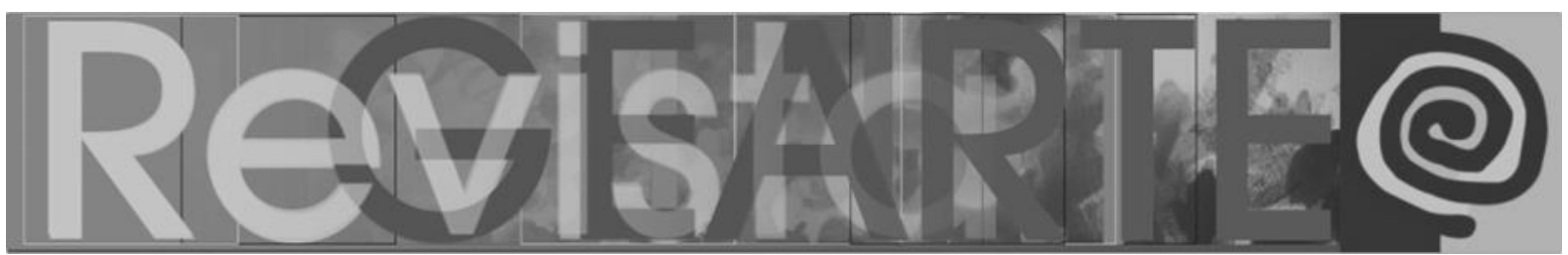

pesquisa (ROMANOWSKI; ENS, 2006; FIORENTINI, 1994; FERREIRA, 2002) ou são, também, denominados estudos do estado do conhecimento (SOARES, 1989; ANDRÉ, 2002). Entendemos, na pesquisa, os estudos do estado da arte da pesquisa, ou do estado do conhecimento, como aqueles que envolvem número de trabalhos expressivos e que buscam descrever aspectos mais gerais da pesquisa em um determinado objeto, no nosso caso, da Arte na Pedagogia, destacando seus principais resultados - inacabados - e fazendo um balanço-síntese do conhecimento produzido, ainda como resultado parcial nessa temática.

Em relação a nossa pesquisa, corrobora Romanowski; Ens (2006), com a discussão ao dizer que o estado da arte, em suas palavras,

[...] pode significar uma contribuição importante na constituição do campo teórico de uma área de conhecimento, pois procuram identificar os aportes significativos da construção da teoria e prática pedagógica, apontar as restrições sobre o campo em que se move a pesquisa, as suas lacunas de disseminação, identificar experiências inovadoras investigadas que apontem alternativas de solução para os problemas da prática e reconhecer as contribuições da pesquisa na constituição de propostas na área focalizada. (ROMANOWSKI; ENS, 2006, p. 39)

O estado da arte contribui para desvendar e examinar o conhecimento que já foi produzido na área, apontando os enfoques e temas mais discutidos. É um balanceamento que possibilita contribuir com a organização e análise na definição do campo, indicando novas possibilidades de pesquisa.

Para Romanowski e Ens (2006), realizar uma pesquisa do tipo estado da arte, parte-se dos seguintes procedimentos:

[...] definição dos descritores para direcionar as buscas a serem realizadas;- localização dos bancos de pesquisas, teses e dissertações, catálogos e acervos de bibliotecas, biblioteca eletrônica que possam proporcionar acesso a coleções de periódicos, assim como aos textos completos dos artigos; estabelecimento de critérios para a seleção do material que compõe o corpus do estado da arte; levantamento de teses e dissertações catalogadas; coleta do material de pesquisa, selecionado junto às bibliotecas d\}e sistema COMUT ou disponibilizados eletronicamente; leitura das publicações com elaboração de síntese preliminar, considerando o tema, os objetivos, as problemáticas, metodologias, conclusões, e a relação entre o pesquisador e a área; organização do relatório do estudo compondo a sistematização das 


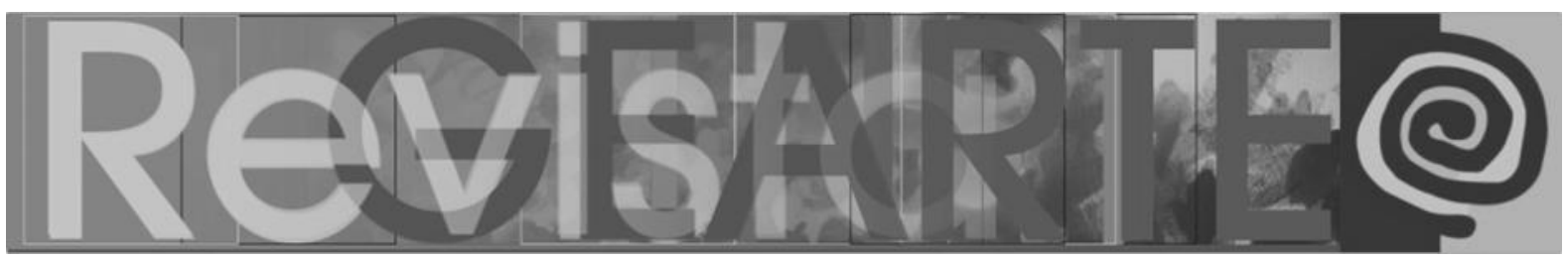

sínteses, identificando as tendências dos temas abordados e as relações indicadas nas teses e dissertações; análise e elaboração das conclusões preliminares. (ROMANOWSKI; ENS, 2006, p. 43)

Nesta direção, iniciamos ao elencar os descritores: Arte, Pedagogia, Arte na Pedagogia, Pedagogia e Arte, Currículo e Arte na Pedagogia, tendo em vista o objetivo pretendido de mapear os cursos de licenciatura em Pedagogia no Brasil e o estado da arte e do conhecimento das produções da Arte na Pedagogia. Posteriormente, foi localizado o banco de dados para a pesquisa diretamente das fontes e dos termos descritores dessa localização, para coletar os dados no banco de teses e de dissertações da Capes, bem como nos portais dos programas de pós-graduação, no portal do E-mec, em revistas científicas e em artigos em anais de eventos nos últimos doze anos - mais precisamente de 2006 até 2018. Depois de localizada, a produção acadêmica foi lida e, na sequência, realizamos um inventário descritivo e interpretativo para as análises.

Para os resultados dessa pesquisa - do mapeamento dos cursos de Licenciatura em Pedagogia- recorremos a dados que foram coletados, inicialmente, no site do e-mec. Tomamos conhecimento pela pesquisa realizada, de que o Brasil, em 2018, tem 2.752 cursos de Licenciatura em Pedagogia, abrangendo a modalidade presencial e à distância (ver tabela 1). Alguns dos cursos são ofertados em instituições públicas e outros em instituições privadas. Assim, são cursos implantados em universidades, faculdades isoladas, centros universitários, fundações universitárias e polos universitários.

Um avanço considerável de cursos de Pedagogia no Brasil, se comparado ao estudo do panorama dos cursos de Pedagogia apresentado em 2015 por Martins e Lombardi (2015), no qual as autoras demonstram que, em 2012, o país possuía 1.557 cursos de Pedagogia. Já em 2015, três anos depois, já são 1.703 cursos, segundo os dados do Ministério da Educação, isto é, um aumento de 146 novos cursos. 


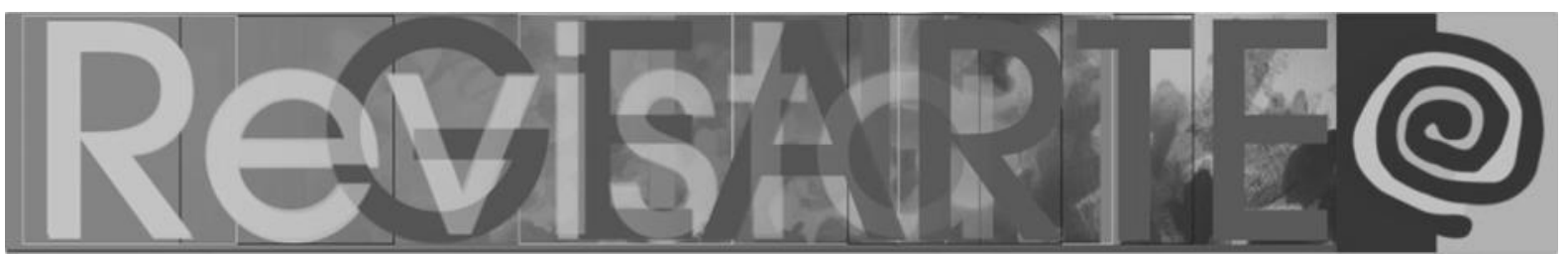

Nessa perspectiva, apresentamos o número de cursos de Pedagogia distribuídos nas regiões do Brasil: sul, sudeste, nordeste, centro oeste e norte. Isso pode ser visto na tabela 1, abaixo:

Tabela 1 - Mapeamento dos cursos de licenciatura em pedagogia no Brasil, em 2018

\begin{tabular}{|c|c|c|c|c|c|c|}
\hline $\begin{array}{c}\text { REGIÕES } \\
\text { DO BRASIL }\end{array}$ & ESTADOS & $\begin{array}{c}\text { № DE } \\
\text { CURSOS }\end{array}$ & $\%$ & MODALIDADE & $\begin{array}{c}\text { № TOTAL } \\
\text { POR } \\
\text { MODALIDADE }\end{array}$ & $\%$ \\
\hline \multirow[t]{8}{*}{ SUL } & \multirow[t]{2}{*}{ Paraná } & \multirow[t]{2}{*}{183} & \multirow[t]{2}{*}{$7 \%$} & Presencial & 119 & $45 \%$ \\
\hline & & & & EAD & 64 & $35 \%$ \\
\hline & \multirow{2}{*}{$\begin{array}{c}\text { Santa } \\
\text { Catarina }\end{array}$} & \multirow[t]{2}{*}{97} & & Presencial & 39 & \\
\hline & & & & EAD & 58 & \\
\hline & \multirow{2}{*}{$\begin{array}{l}\text { Rio Grande } \\
\text { do Sul }\end{array}$} & \multirow[t]{2}{*}{112} & & Presencial & 54 & \\
\hline & & & & EAD & 58 & \\
\hline & \multirow[t]{2}{*}{ Total } & \multirow[t]{2}{*}{392} & \multirow[t]{2}{*}{$14 \%$} & Presencial & 212 & $54 \%$ \\
\hline & & & & EAD & 180 & $46 \%$ \\
\hline \multirow[t]{10}{*}{ SUDESTE } & \multirow{2}{*}{$\begin{array}{l}\text { Espírito } \\
\text { Santo }\end{array}$} & \multirow[t]{2}{*}{90} & & Presencial & 46 & \\
\hline & & & & EAD & 44 & \\
\hline & \multirow{2}{*}{$\begin{array}{l}\text { Minas } \\
\text { Gerais }\end{array}$} & \multirow[t]{2}{*}{235} & & Presencial & 154 & \\
\hline & & & & EAD & 81 & \\
\hline & \multirow{2}{*}{$\begin{array}{l}\text { Rio de } \\
\text { Janeiro }\end{array}$} & \multirow[t]{2}{*}{131} & & Presencial & 66 & \\
\hline & & & & EAD & 65 & \\
\hline & \multirow[t]{2}{*}{ São Paulo } & \multirow[t]{2}{*}{408} & & Presencial & 246 & \\
\hline & & & & EAD & 162 & \\
\hline & \multirow[t]{2}{*}{ Total } & \multirow[t]{2}{*}{864} & \multirow[t]{2}{*}{$31 \%$} & Presencial & 512 & $59 \%$ \\
\hline & & & & EAD & 352 & $41 \%$ \\
\hline \multirow{20}{*}{ NORDESTE } & Alagoas & 56 & & Presencial & 14 & \\
\hline & & & & EAD & 42 & \\
\hline & Bahia & 235 & & Presencial & 154 & \\
\hline & & & & EAD & 81 & \\
\hline & Ceará & 91 & & Presencial & 35 & \\
\hline & & & & EAD & 56 & \\
\hline & Maranhão & 85 & & Presencial & 34 & \\
\hline & & & & EAD & 51 & \\
\hline & Paraíba & 55 & & Presencial & 13 & \\
\hline & & & & EAD & 42 & \\
\hline & Pernambuco & 102 & & Presencial & 52 & \\
\hline & & & & EAD & 50 & \\
\hline & Piauí & 69 & & Presencial & 24 & \\
\hline & & & & EAD & 45 & \\
\hline & Rio Grande & 48 & & Presencial & 12 & \\
\hline & do Norte & & & EAD & 36 & \\
\hline & Sergipe & 44 & & Presencial & 15 & \\
\hline & & & & EAD & 29 & \\
\hline & Total & 785 & $29 \%$ & Presencial & 353 & $45 \%$ \\
\hline & & & & EAD & 432 & $55 \%$ \\
\hline CENTRO & Distrito & 87 & & Presencial & 39 & \\
\hline OESTE & Federal & & & EAD & 48 & \\
\hline & Goiás & 114 & & Presencial & 56 & \\
\hline & & & & EAD & 58 & \\
\hline
\end{tabular}

NUNES, Ana Luiza Ruschel; BULATY, Andréia. Mapeamento dos cursos 608 de Pedagogia e do estado da arte sobre indicadores da Arte na Pedagogia. Revista GEARTE, Porto Alegre, v. 8, n. 2, p. 602-625, maio/ago. 2021. Disponível em: http://seer.ufrgs.br/gearte 


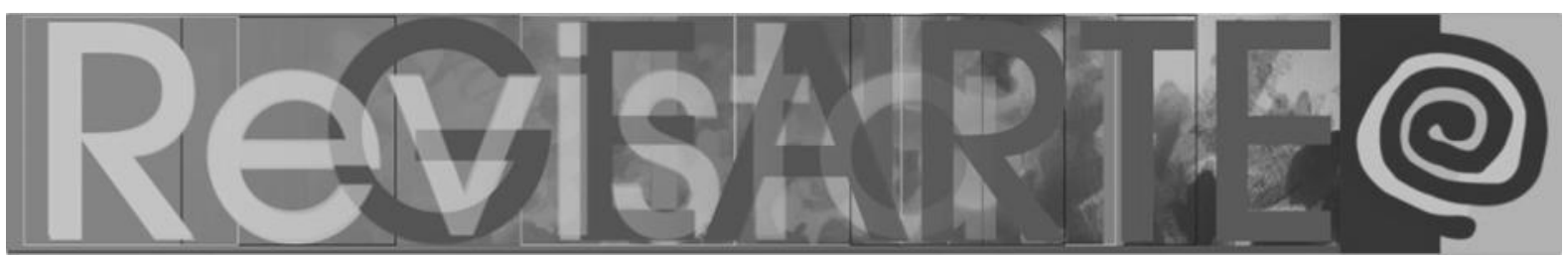

\begin{tabular}{|c|c|c|c|c|c|c|}
\hline & \multirow{2}{*}{$\begin{array}{c}\text { Mato } \\
\text { Grosso }\end{array}$} & \multirow[t]{2}{*}{81} & \multirow[t]{2}{*}{1} & Presencial & 30 & \\
\hline & & & & EAD & 51 & \\
\hline & \multirow{2}{*}{$\begin{array}{c}\text { Mato } \\
\text { Grosso do } \\
\text { Sul }\end{array}$} & \multirow{2}{*}{80} & & Presencial & 26 & \\
\hline & & & & EAD & 54 & \\
\hline & \multirow[t]{2}{*}{ Total } & \multirow[t]{2}{*}{362} & \multirow[t]{2}{*}{$13 \%$} & Presencial & 151 & $42 \%$ \\
\hline & & & & EAD & 211 & $58 \%$ \\
\hline \multirow[t]{16}{*}{ NORTE } & \multirow[t]{2}{*}{ Acre } & \multirow[t]{2}{*}{34} & & Presencial & 4 & \\
\hline & & & & EAD & 30 & \\
\hline & \multirow[t]{2}{*}{ Amapá } & \multirow[t]{2}{*}{37} & & Presencial & 9 & \\
\hline & & & & EAD & 28 & \\
\hline & \multirow{2}{*}{ Amazonas } & \multirow[t]{2}{*}{63} & & Presencial & 17 & \\
\hline & & & & EAD & 46 & \\
\hline & \multirow[t]{2}{*}{ Pará } & \multirow[t]{2}{*}{84} & & Presencial & 35 & \\
\hline & & & & EAD & 49 & \\
\hline & \multirow[t]{2}{*}{ Rondônia } & \multirow[t]{2}{*}{56} & & Presencial & 19 & \\
\hline & & & & EAD & 37 & \\
\hline & \multirow[t]{2}{*}{ Roraima } & \multirow[t]{2}{*}{27} & & Presencial & 6 & \\
\hline & & & & EAD & 21 & \\
\hline & \multirow[t]{2}{*}{ Tocantins } & \multirow[t]{2}{*}{48} & & Presencial & 15 & \\
\hline & & & & EAD & 33 & \\
\hline & \multirow[t]{2}{*}{ Total } & \multirow[t]{2}{*}{349} & \multirow[t]{2}{*}{$13 \%$} & Presencial & 105 & $30 \%$ \\
\hline & & & & EAD & 244 & $70 \%$ \\
\hline \multirow{2}{*}{$\begin{array}{l}\text { TOTAL } \\
\text { BRASIL }\end{array}$} & \multirow[t]{2}{*}{2752} & & Presencial & 1333 & $48 \%$ & \\
\hline & & & $E A D$ & 1389 & $52 \%$ & \\
\hline
\end{tabular}

Fonte: Elaborado pelas pesquisadoras com base no site do E- mec: http://emec.mec.gov.br/ (2018).

A partir dos dados da tabela 1, constatamos que, no Brasil, há um número significativo de cursos de Pedagogia na modalidade presencial e EaD. Como já fora referido, são, até 2018, um total de 2.752, o que mostra um aumento de 1.049 novos cursos em comparação com 2015, quando eram 1.703 cursos de Pedagogia no território nacional (MARTINS; LOMBARDI, 2015). É uma rede que está em crescente demanda, o que inspira olhares atentos para a qualidade dos processos formativos dos pedagogos formados.

Fica perceptível que a região norte apresenta a menor quantidade de cursos, $13 \%$ do total nacional, devido às condições de estrutura, espaço e organização social. Mas, por outro lado, nos chama a atenção o fato de que ela é uma das regiões na qual o ensino à distância $(\mathrm{EaD})$ tem avançado nos últimos anos, atingindo $70 \%$, em oposição aos $30 \%$ do ensino presencial. O estudo realizado por Martins e Lombardi (2015) detectou que as regiões Norte e Nordeste apresentavam altos índices de cursos na modalidade EaD. 


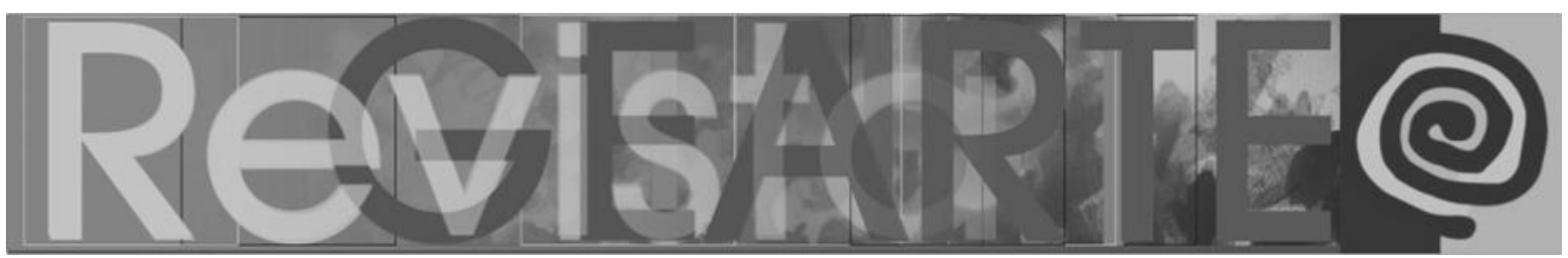

Acredita-se que o avanço tecnológico e a demanda crescente de instituições de ensino privado têm contribuído para o EaD. Esse método traz, para a educação, a possibilidade do aluno estudar em casa, no seu tempo e espaço, sem precisar ir à sede/campus das Instituições de Ensino Superior (IES) todos os dias.

No Brasil, cerca de $48 \%$ dos cursos de Pedagogia são presenciais e $52 \%$ são EAD. Nesse ínterim, questiona-se: o curso de Pedagogia presencial tem contribuído para uma formação cultural ou semiformação dos professores para atuar na educação infantil e ensino fundamental I? Como a formação cultural e/ou semiformacão cultural está sendo concebida no curso de Pedagogia na modalidade de EAD? Proporcionar experiências e vivências para aprendizagens ainda são ações desafiadoras nessa modalidade EaD, especialmente ao se pensar o conceito de infância e os processos criativos na formação do pedagogo.

Assim, as dúvidas se manifestam, de forma propositiva e aberta. Acirramse profissionais, gestores e demais envolvidos nessa formação, pois, ao realizarem debates, argumentos, ações e práticas educativas em arte em grupo, e de forma colaborativa, à distância, podem, muitas vezes, gerar inseguranças na prática docente e no campo de atuação profissional futura. Como será que o futuro pedagogo de $\mathrm{EaD}$ realiza essas relações? Como pensar o objeto desta pesquisa no ensino de EaD? Como é o currículo dos cursos de licenciatura em pedagogia na EaD? E a arte nesse currículo, assim como a aprendizagem na formação inicial do professor, na EaD? Esses são questionamentos que abrem espaço para futuras pesquisas sobre a arte nos cursos de Pedagogia à distância.

É importante destacarmos que a região norte concentra a maioria dos cursos EaD de Pedagogia (70\%), sendo que o ensino presencial ocupa $30 \%$ da formação docente. Em um ranking geral do país, a região Sul fica em 3ำ lugar no número de oferta de cursos de pedagogia, com $14 \%$ dos cursos. Deste total, a educação presencial é maior que a EAD, cerca de $54 \%$ são presenciais e $46 \%$ são 


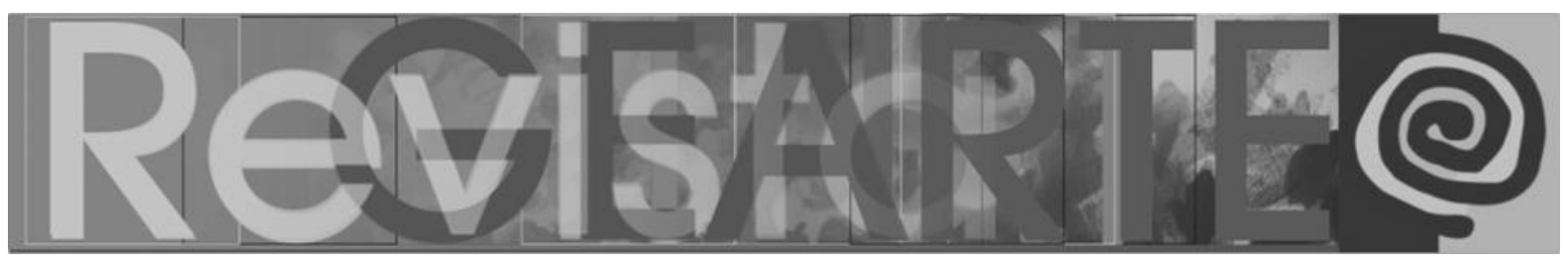

à distância. $\mathrm{O}$ estado do Paraná possui $7 \%$ dos cursos de Pedagogia no país, com $54 \%$ de educação presencial.

Assim, questiona-se: a arte, as vivências e experiências estéticas em artes visuais, dança, música e teatro estão presentes no curso de Pedagogia? Qual a contribuição dessas linguagens e expressões criativas do campo do conhecimento e nas práticas criativas e expressivas em arte, nos cursos de Pedagogia? Questões essas que podem ser desveladas por pesquisas do estado do conhecimento sobre a Arte e a Pedagogia.

\section{Estado do Conhecimento da Arte na Pedagogia}

Após termos acesso a estes dados da realidade nacional e do estado do Paraná, direcionamos esforços para conhecermos o que se tem produzido sobre o tema, já que estudos sobre as disciplinas relativas ao método de ensino são pouco ou quase nada pesquisadas no curso de licenciatura em Pedagogia. Nesse sentido, empreendemos a busca para conhecer e elaborar um mapeamento das produções cientificas da área que tratam da arte no curso de Licenciatura em Pedagogia. Utilizamos os dados coletados no banco de teses e dissertações da Capes, nos portais dos programas de pós-graduação e nas revistas científicas, esquadrinhado pelos descritores: Arte, Pedagogia, Arte na Pedagogia, Pedagogia e Arte, Currículo de Arte na Pedagogia.

Realizamos a pesquisa nos últimos 12 anos, mais precisamente de 2006 a 2018. Foram encontrados, ao todo, 43 pesquisas, entre dissertações, teses e artigos científicos em periódicos e anais. Apresentam a relação da arte com a pedagogia, um número baixo de produções considerando os 2.752 cursos de graduação em pedagogia no país. Esse dado demonstra que a arte é um campo ainda a ser investigado na pedagogia. Isto é, ele necessita da pesquisa com uma demanda de grande de questões a serem problematizadas e, também, com assuntos, ou temas de pesquisa, que abrangem tanto os campos epistemológicos de pesquisa quanto os campos epistemológicos da Pedagogia e da Arte em suas 


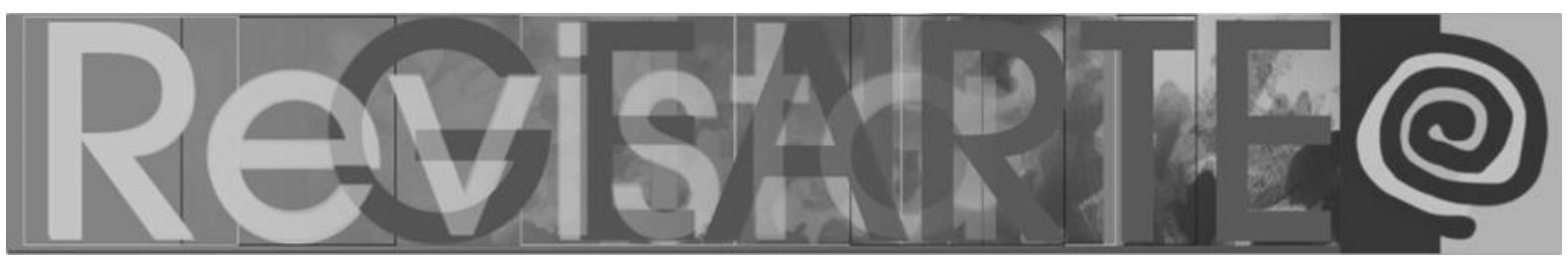

diferentes expressões e linguagens, como artes visuais, dança, música e teatro em sua hibridização com o jogo de regras, jogo protagonizado, jogo simbólico e, ainda, o brinquedo, a brincadeira e o brincar e, ainda, as práticas e metamorfoses expressivas e criativas no desenvolvimento e na aprendizagem. Esse campo necessitaria de uma demanda de pesquisa sobre e da infância e a práxis de poéticas criativas e expressivas em Artes, cuja recomendação é a disposição de espaços de ateliê de arte para a formação de professores. Em decorrência, seria necessário criar um espaço de ateliê de arte na infância para a construção de identidades infantis com significado para poéticas (BULATY; ADENA, 2017).

Igualmente, demanda-se pesquisas com os princípios teóricos e práticos, com os processos cognitivos, afetivos, sociais, estéticos e culturais e das vivências e experiências estéticas, reflexivas e críticas com Arte. Assim, mapeou-se artigos em periódicos, em anais de evento, teses, dissertações. A tabela 2 apresenta essa produção especificada em cada ano, conforme segue.

Tabela 2 - Produção científica sobre e das Artes Visuais na Pedagogia

\begin{tabular}{|c|c|c|c|c|c|}
\hline Ano & $\begin{array}{l}\text { Artigos em } \\
\text { Revistas }\end{array}$ & $\begin{array}{ll}\text { Artigo em } \\
\text { anais de } \\
\text { evento }\end{array}$ & Tese & Dissertação & Total \\
\hline 2018 & 1 & 3 & & & 4 \\
\hline 2017 & 2 & 2 & & 1 & 5 \\
\hline 2016 & 1 & 3 & 1 & 3 & 8 \\
\hline 2015 & 5 & 1 & 1 & 1 & 8 \\
\hline 2014 & 2 & 1 & & & 3 \\
\hline 2013 & 1 & & & & 1 \\
\hline 2012 & & 1 & 1 & & 2 \\
\hline 2011 & 1 & & & 2 & 3 \\
\hline 2010 & 2 & & & & 2 \\
\hline 2009 & & & 1 & 1 & 2 \\
\hline 2008 & & & & 2 & 2 \\
\hline 2007 & & & & 2 & 2 \\
\hline 2006 & 1 & & & & 1 \\
\hline Total & 16 & 11 & 4 & 12 & 43 \\
\hline
\end{tabular}

Fonte: Elaborada pelas pesquisadoras com base na coleta do estado da arte (2018).

As produções apresentam um campo frágil em pesquisas na pós-graduação strictu sensu, com apenas 4 teses e 12 dissertações. Um número pequeno, pois, nesse espaço de 2006 a 2018, tem-se a discussão sobre e da formação de futuros 


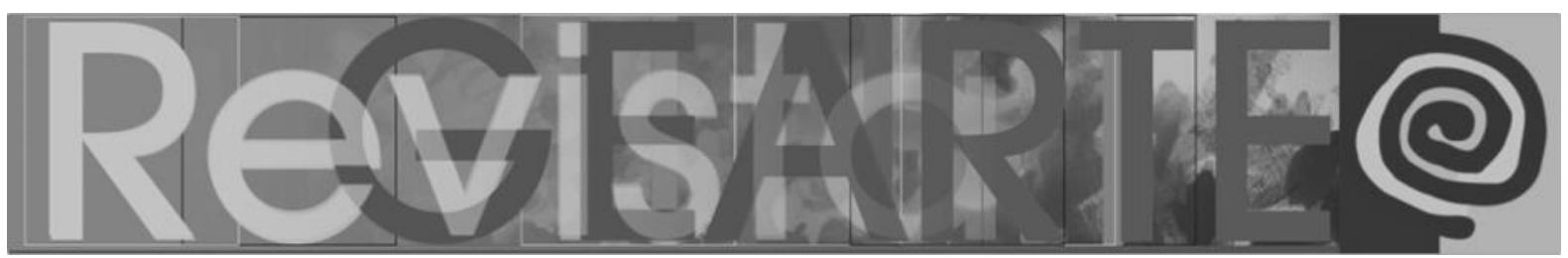

docentes à frente dos cursos de Pedagogia, contribuindo diretamente com a formação de futuros pedagogos.

Com o pequeno número de pesquisas na área, é prudente dizer que há uma desvalorização das artes na formação do pedagogo, a começar pela reduzida carga horária da disciplina nas matrizes curriculares dos projetos pedagógicos dos cursos de pedagogia (ARAÚJO, 2015; PIMENTA et al., 2017), acompanhada de uma fragmentação curricular (MOMOLI; EGAS, 2015). Além disso, há o fato de que alguns docentes que ministram as aulas de arte na graduação não são habilitados em cursos de licenciatura de arte (FIGUEIREDO, 2017). A formação dos pedagogos, em grande parte, é pautada na racionalidade técnica (VIDAL, 2011; AGUIAR, 2018) e se oferece, predominantemente, em quase todos os cursos de Pedagogia, o pouco espaço para as disciplinas relacionadas à arte nos cursos de pedagogia (ARAÚJO, 2015).

Com essa pesquisa do estado da arte e do estado do conhecimento intencionou-se discutir um tema pouco - ou quase - nada pesquisado sobre a formação do/a Pedagogo/a, na tentativa de rever e repensar o currículo dos cursos de pedagogia e, do mesmo modo, contribuir para a educação com as artes. Nesse sentido, esperamos colaborar para emergir, na formação do pedagogo, condições para o desenvolvimento e para a aprendizagem de conhecimentos que não coloquem a arte na condição de simples reprodução/imitação e cópia enquanto processos formativos, mas, sim, a arte como um trabalho criador e expressivo. Da mesma forma, espera-se que na formação do pedagogo não considerar as experiências artísticas e estéticas das artes sob a perspectiva teórica estruturalista e pragmática de uma arte sob a racionalidade técnica simplesmente. Ainda, no processo de formação, o pedagogo deve não considerar a arte apenas como formação da subjetividade, da estética - somente como sensibilidade que vem de dentro para fora -, da emoção, do sensível, ou seja, deve-se possibilitar, à criança e ao pré-adolescente, uma formação cultural que não permita o retorno ao positivismo e não limita a uma semiformação. 


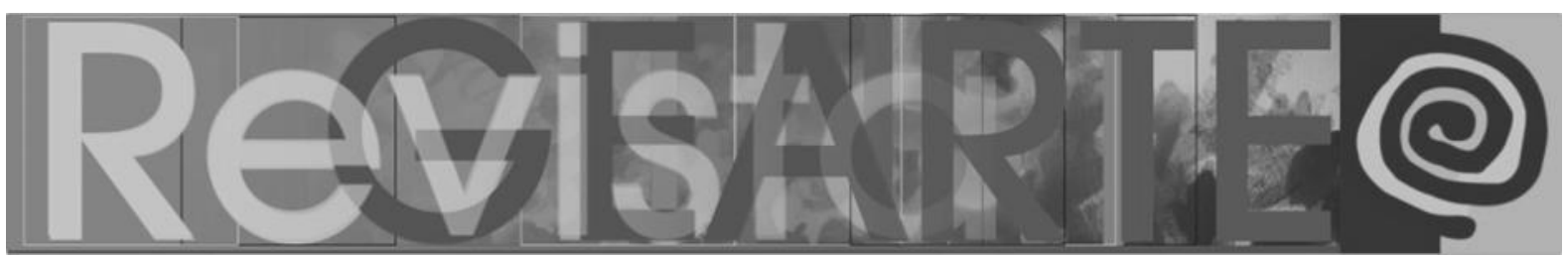

$\mathrm{Na}$ abordagem de Adorno (1996) corroboram dois conceitos importantes para formação de pedagogos: a formação cultural e a semiformação cultural. A formação cultural diz respeito ao sujeito livre e radicado em sua própria consciência, sendo condição implícita para uma sociedade autônoma e emancipatória, que quanto mais lúcido for o singular (homem), mais lúcido será o todo (social), atuando de forma crítica/consciente/participativa na sociedade democrática que se almeja. Contrário a esse pensamento, o processo de semiformação, ou semiformativo, conhecido por "[...] semicultura" (ADORNO, 1996), é a "[...] difusão de uma produção simbólica onde predomina a dimensão instrumental voltada para a adaptação e o conformismo, subjugando a dimensão emancipatória que se encontra 'travada' [...]" (ZUIN; PUCCI; OLIVEIRA, 2008. p. 58).

A opção em estudar esse tema ainda limitado foi um desafio para entender a inserção das linguagens das artes na pedagogia. No entanto, desconhecer como estava configurada a arte nos cursos de pedagogia, em sua totalidade, foi desvelado pela pesquisa. Por isso a necessidade do estado da arte: para conhecermos as produções nesse campo e avançarmos no que ainda não foi estudado e pesquisado, perpassando o já conhecido para compreender o não visível, ou seja, aquilo que, para nós pesquisadores, ainda estava oculto - ou, ainda, a invisibilidade da arte nos currículos dos cursos de Pedagogia.

Ao pesquisar, sob a indicação do descritor Arte/Pedagogia, ficaram visíveis os temas de pesquisa que relacionam a arte e a pedagogia. Constatamos, assim, que os trabalhos discutem o ensino da Arte na Pedagogia em diferentes contextos e situações. Nenhuma pesquisa, no entanto, de modo específico, aborda sobre o currículo com a Arte na Pedagogia, o que se tem é o ensino da Arte na Pedagogia. Também, nos chama a atenção que nenhuma pesquisa discute o tema tendo os fundamentos epistemológicos da Teoria Crítica sob a abordagem de Adorno (2010; 2000; 1996; 1995) e Adorno e Horkheimer (1985), que aborda a dialética negativa e nega o positivismo. 


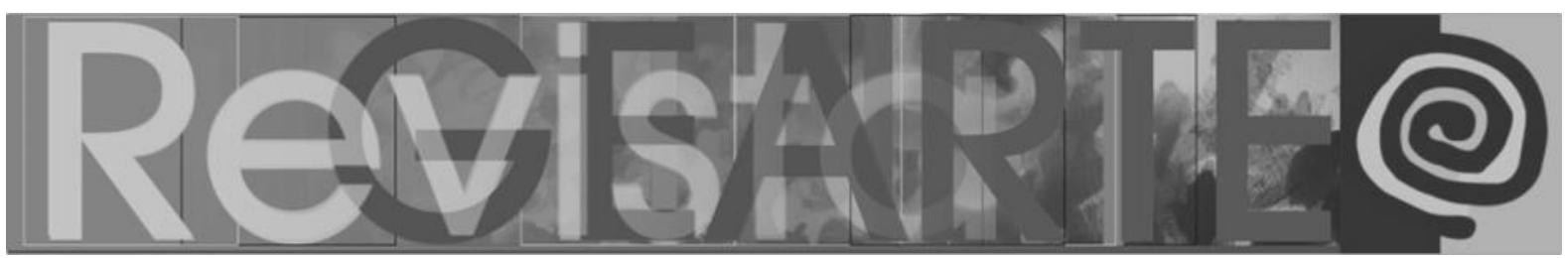

São pesquisas científicas que discutem a Arte na Pedagogia utilizando-se de abordagens, ora voltados para o ensino da arte, ora voltados para a formação de professores, conforme fica explícito na nuvem de palavras, que mostra os autores que são mais citados nas produções científicas como teses, dissertações e artigos, entre os anos de 2006 a 2018. Isso pode ser visualizado na figura:

Figura 1 - Autores mais citados nas produções, entre os anos de 2006 a 2018

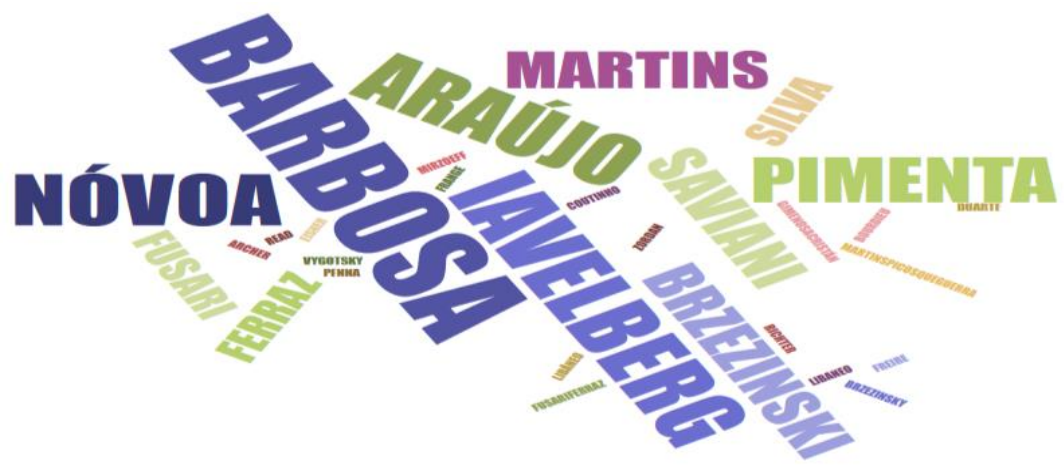

Fonte: Nuvem elaborada pelas pesquisadoras com auxílio do site de Word Cloud Generator ${ }^{1}$ (2018).

A figura 1 apresenta os autores das produções científicas que, com maior grau de frequência, discutem a Arte na Pedagogia nos últimos 12 anos, com ênfase no ensino da arte. Como já mencionado na nuvem, destaca-se as autoras Barbosa, lavelberg, Martins e Araújo. $\mathrm{Na}$ área de formação de professores temos os estudos de Nóvoa, Pimenta, Saviani e Brzezinski, que contribuem com estudos e pesquisas sobre a formação do pedagogo. No entanto, vale mencionar a pesquisa de Romero e Nunes (2017), que traz os processos colaborativos de investigação-ação como caminho para a formação de professores da educação infantil, construindo possibilidades compartilhadas de pesquisa e ensino; também, Bulaty e Nunes (2020), que pesquisaram, recentemente, o currículo dos cursos de pedagogia e a inserção da Arte, artes visuais, na Pedagogia.

Em geral, os autores mencionados na figura 1 tem pesquisas e discussões sobre diferentes temáticas que vão desde políticas e pedagogia, de arte na pedagogia, de ensino da arte na formação de professores e de metodologias do ensino das artes na pedagogia. Após a proximidade dos estudos analisados em entender a arte e a pedagogia, verificamos que os termos mais utilizados nas 


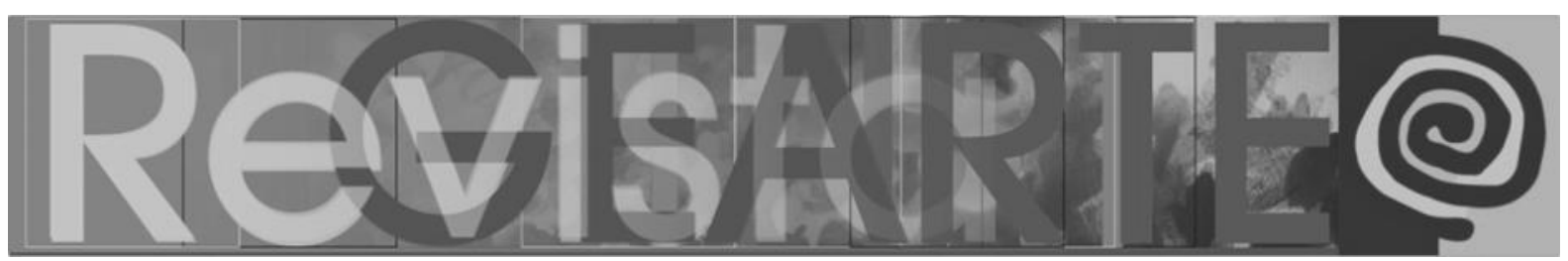

pesquisas relevam debates que se embasam na dupla discussão do ensino da Arte e Pedagogia (Figura 2), sendo esta referenciada pelos autores citados na figura 1.

Figura 2 - Palavras-chave mais usadas nas produções entre 2006 a 2018

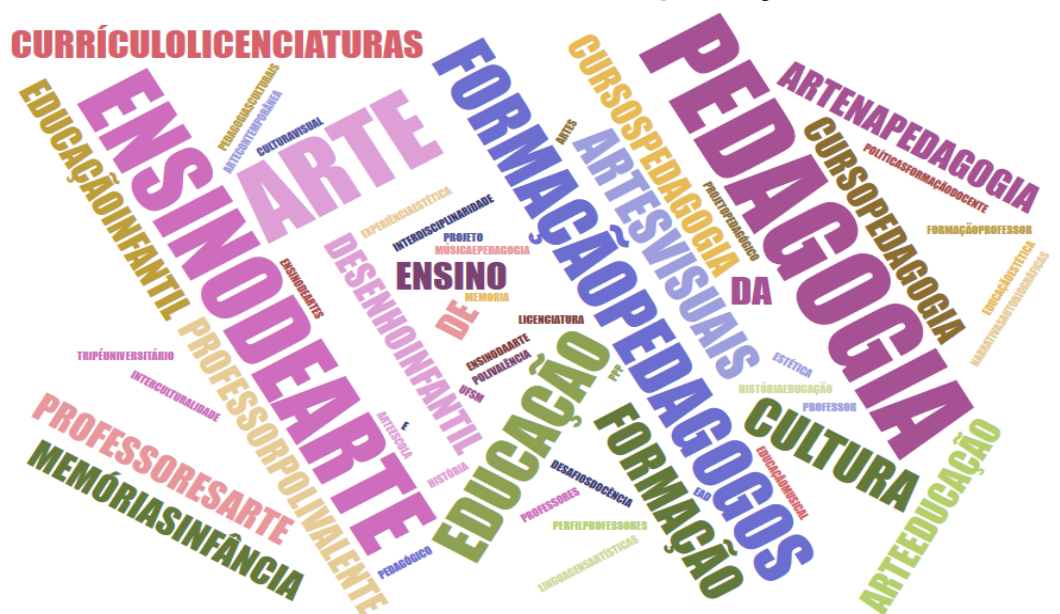

Fonte: Nuvem elaborada pelas pesquisadoras com auxílio do site de Word Cloud Generator (2018).

Em evidência, com maior frequência aparece a palavra pedagogia e o ensino da arte, acompanhado das palavras educação, formação, cultura, arte, formação dos pedagogos e artes visuais. As 43 produções de pesquisa encontradas se utilizam dessas temáticas de estudo e têm contribuído muito para a formação do pedagogo.

Os estudos e pesquisas chamam atenção de se olhar para a formação do pedagogo para aprender e ensinar a arte na educação infantil e nos anos iniciais da educação básica. A arte nos cursos de pedagogia conquista espaço com as Diretrizes Curriculares Nacionais para o Curso de Pedagogia (BRASIL, 2006), uma vez que ela é incorporada aos currículos dos cursos como um campo de conhecimento, que é essencial para a formação do pedagogo, abrangendo a dimensão estética, cultural e artística, e o ensino de arte.

A partir desse documento oficial questiona-se: como a linguagem da arteartes visuais está presente na formação do pedagogo? A arte é um instrumento pedagógico ou um conhecimento com conteúdos específicos? Qual espaço se materializa às artes visuais nos currículos dos cursos de Pedagogia? 


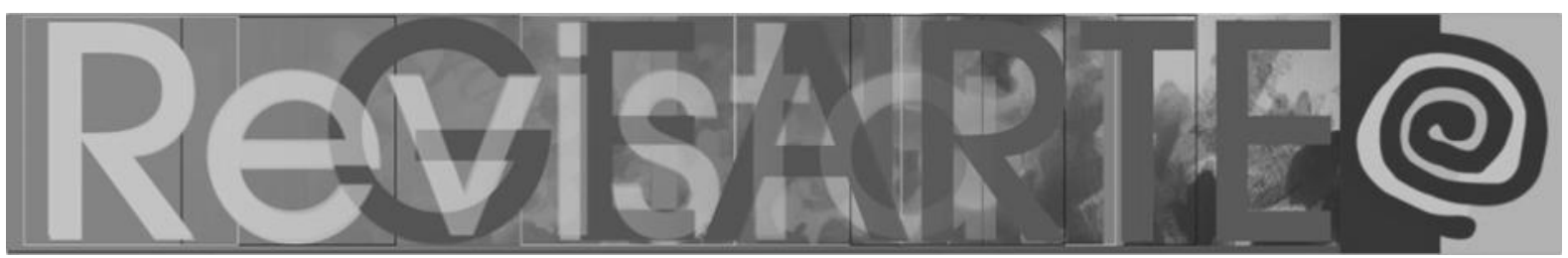

Essas questões problematizadoras são pontuais nas pesquisas realizadas, segundo os descritores. Até o presente momento, elas propiciam um olhar preliminar, pois continuamos a pesquisar, em movimento histórico, o tema da arte na pedagogia de forma cada vez mais intensa.

O mapeamento do estado da arte e do conhecimento sobre e do currículo e da Arte na Pedagogia contribui para um mapeamento cartográfico e para a consolidação do presente estudo e pesquisa. Dessa forma, entendemos e compreendemos a necessidade das artes e, também, percebemos, até aqui, que a arte é pouco pesquisada pelos pedagogos.

Mirian Celeste Martins (2015a) defende que a arte na pedagogia é um movimento novo que busca encontrar espaço, mesmo sendo preciso tempo para instaurar sua permanência e suas transformações no ambiente de formação. Nessa perspectiva, a presente pesquisa serve de referência para pensar os currículos dos cursos de licenciatura em Pedagogia do estado do Paraná e seus desafios, quais as concepções sobre a arte, quais posicionamentos epistemológicos estão presentes e como se dá sua organização enquanto área de conhecimento.

Outra pesquisa que ganha destaque é de Fabíola Cristina Alves (2018). A pesquisadora defende que o desafio do ensino de arte é tanto o reconhecimento da autonomia de seu conhecimento quanto a sua consolidação na formação dos pedagogos. Essa visão desencadeia uma das preocupações com o currículo, com o quê ensinar e com como e por que ensinar arte nos cursos de pedagogia.

O estudo de Luciana Esmeralda Ostetto e Greice Duarte de Brito Silva (2018) traz a discussão sobre a necessidade de aproximação entre arte e educação realizada pelo campo da pedagogia e, essencialmente, na formação de professores, traçando a (re) aproximação do pensar e sentir como dimensões que nos constituem enquanto ser. Também, o estudo estimula a criação, a apreciação, a transformação, o movimento, a possibilidade de escolha, a liberdade de 


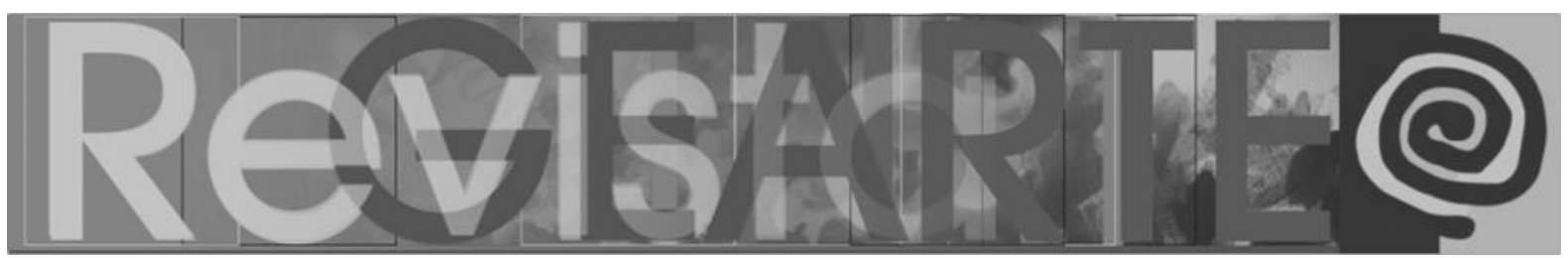

expressão, bem como a ampliação de repertórios que são potencializados, ao incluir as dimensões estética e cultural no projeto pedagógico do curso.

A produção científica de Daniel Momoli e Olga Egas (2015) confirma que a arte aparece em alguns currículos como disciplina(s) de ensino da arte na formação do pedagogo. Destaca-se que, ainda, a arte está aparecendo nesses espaços, devido à dificuldade para a implementar, na pedagogia, uma formação no campo das artes que vá além da transposição dos saberes artísticos técnicos e de conhecer artistas. Segundo Momoli e Egas (2015), tal formação deveria proporcionar a vivência curricular com o campo específico de conhecimento da arte, mas, na grande maioria, limita-se a uma ou duas disciplinas, sem propiciar um processo lento e gradativo - que envolve a recepção, a produção, a mediação, a contextualização e os fundamentos da arte.

Nesse sentido, somos conduzidos a ponderar, assim como Momoli e Egas (2015), ao defenderem que a formação do professor que vai ensinar arte implica a apropriação dos elementos específicos do universo artístico, como a criação, a poética, a fruição e o exercício artístico em especial. Deve-se pensar na formação de saberes específicos e na dimensão da estética, rompendo com a visão de que a colocação da disciplina no currículo seja suficiente para a ação docente de ensinar a arte, a produção de sentidos e a construção de saberes estéticos e culturais.

Quando a arte surgir na formação do pedagogo como processo formativo cultural e estético e seus fundamentos, ela vai contribuir para a saída de uma racionalidade técnica, de uma semiformação, como apontada por Adorno (1995; 1996). Assim, ela vai constituir uma formação cultural, que pode desnaturalizar o olhar sobre o mundo da vida, principalmente os olhares lançados pela escola, que resumem a dimensão estética da arte a meros exercícios de repetição, de técnicas e de reprodução, o que não possibilitam a emancipação crítica humana do homem.

A desnaturalização do olhar do professor ocorre, segundo Momoli e Egas (2015), na desconstrução dos modos de relacionamento com a arte a partir do que 


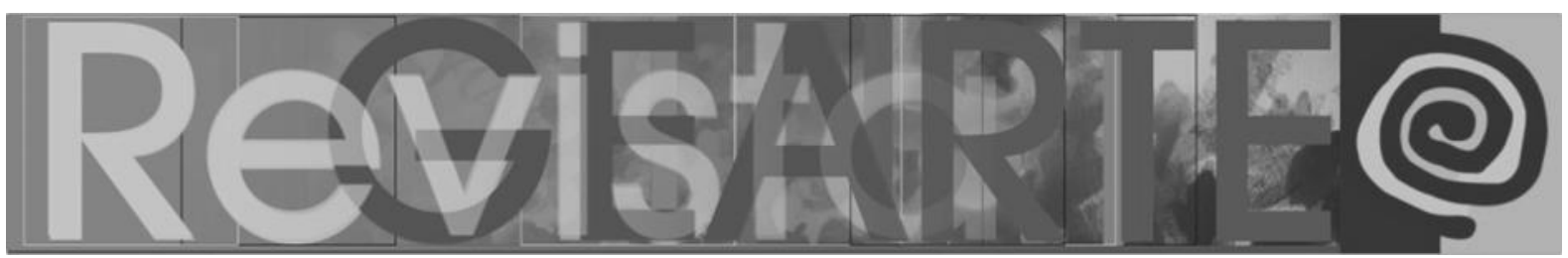

foi constituído ao longo da história, produzindo processos educativos que tencionam a vida, as formas de saber/poder e as linguagens artísticas. Os estudos de Momoli e Egas (2015) contribuem para que possamos pensar a arte como um campo de desnaturalização do olhar do sujeito, para evitar que a educação se torne uma barbárie e para que não mais fiquemos oprimidos pelo raciocínio técnico de uma semiformação, mas, sim, que avancemos para os processos formativos estéticos que a arte pode proporcionar na formação de pedagogos(as).

Na presente pesquisa, o foco recai sobre as artes visuais, porque ela é uma das linguagens da arte que mais é ensinada nas escolas e realizada pelos alunos. Para reafirmar essa opção, amparamo-nos nos estudos de Martins (2015, p. 2326), que concluem que as artes visuais têm sido a rainha das linguagens artísticas. Portanto, estamos interessados em conhecer o que os currículos dos cursos de licenciaturas em Pedagogia vêm pontuando sobre a mesma. Nesse sentido, nos atentamos para o currículo: o que este contempla sobre a arte e as artes visuais? Qual o espaço que a arte e as artes visuais têm nos currículos dos cursos de licenciaturas em Pedagogia?

Assim, destacamos duas pesquisas que discutem o currículo e a arte: os estudos de Figueiredo (2017), Libâneo (2010) e Leite et al. (2018). Figueiredo (2017) destaca o fato de se minimizar a possibilidade de entendimento e o trabalho com a arte, que, tanto na formação inicial dos professores, quanto no ensino básico, restringe-se à arte, a uma única disciplina, com carga horária ínfima. Além disso, os conteúdos envolvem as várias linguagens artísticas ministradas por um único professor, que, na maioria das vezes, não tem formação específica em cada linguagem da arte.

A formação do pedagogo para ensinar arte de forma propositiva para oportunizar processos criativos e poéticos não se sustenta se não houver, como referência, os conteúdos a serem ensinados, a metodologia própria da área específica e as formas de aprendizagem da disciplina, diz Libâneo (2010). Em 


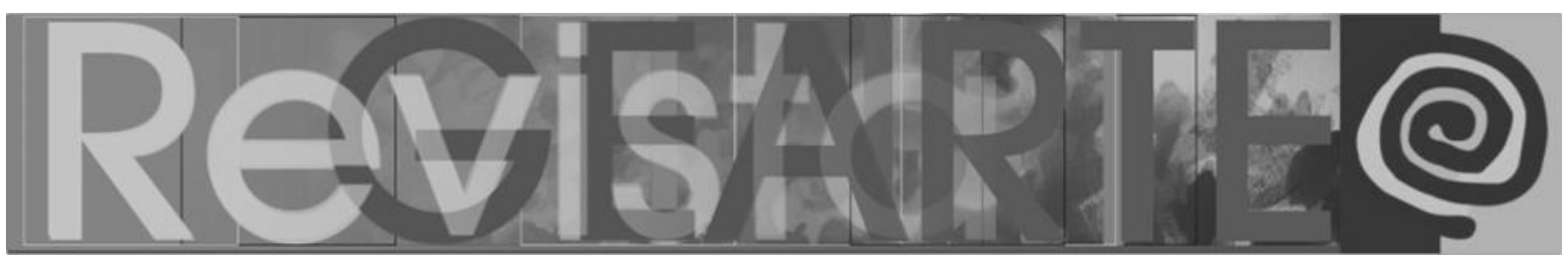

resumo, o curso de Pedagogia precisa prover uma formação que venha a fornecer o domínio e a apropriação de saberes do campo de conhecimento da arte, em suas diferentes linguagens expressivas, em sua forma interdisciplinar e multidisciplinar, na apropriação de metodologias, nos procedimentos e modos de ação propositivos de intervenção, tendo sempre presente a mediação do professor entre a arte e o contexto sócio-histórico-cultural e intercultural em que o ensino se dá. Nessa direção, questiona-se: será que os cursos de pedagogia destinam um espaço significativo no currículo para a disciplina de arte? Quem é o profissional que ministra a formação em arte no curso de pedagogia?

Leite et al. (2018) criticam que uma disciplina de arte no curso de pedagogia não é suficiente para dar conta de seu extenso conteúdo, pois existem diferentes linguagens artísticas (artes visuais, teatro, música e dança), as quais demandam um tempo para o desenvolvimento de cada uma. Somente nas artes visuais, temos, além de saberes, os processos poéticos criativos em pintura, o desenho, a gravura, a fotografia, o cinema, a escultura, a arquitetura, a instalação, a web design, a moda, a decoração, o paisagismo, a novela, enfim. Isto é, somente dentro de uma linguagem, há uma imensidão de conteúdos a serem ensinados, executa uma mediação necessária na formação do pedagogo que vai atuar no campo profissional escolar e não-escolar da educação infantil, dos anos iniciais e do ensino fundamental I.

Esses autores acima nos fazem pensar em como dar conta de todo esse conhecimento em um curto período de tempo. Também, nos fazem pensar em qual pedagogo está sendo habilitado para ensinar artes na educação básica.

Com base nos estudos e pesquisas realizadas até 2018 , foi desvelado, por Figueiredo (2017), que os docentes que ministram aula de arte nos cursos de licenciatura em pedagogia não são habilitados em arte. Por sua vez, o estudo e pesquisa concluído em 2019, publicado em formato de livro (ampliado e revisado), por Bulaty e Nunes (2020), intitulado O currículo e as Artes Visuais nos cursos de 


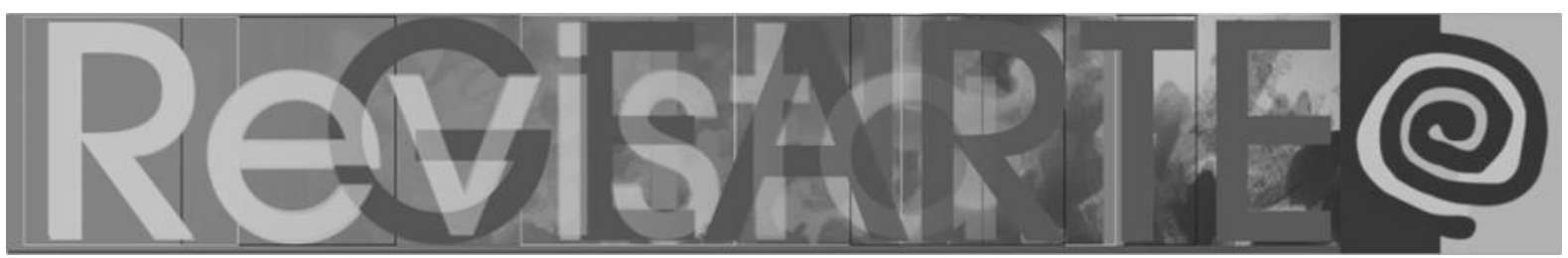

licenciatura em Pedagogia no Estado do Paraná, desvelou muitas questões sobre e das artes visuais na formação do pedagogo. Essa temática de pesquisa teve, como objetivo, analisar os currículos dos cursos de licenciatura em pedagogia do estado do Paraná e, também, analisar como esses currículos compreendem e inserem o conhecimento e a expressão das artes visuais na formação do pedagogo. Esse estudo revela que os currículos inserem a disciplina de arte de forma tênue; na maioria dos casos, ela é ministrada por professores sem formação específica em arte e, ainda mais preocupante: sem formação específica em artes visuais.

$\mathrm{Na}$ análise dos currículos dos cursos de Pedagogia estudados pelas pesquisadoras Bulaty e Nunes (2020), ficou percebível que eles destinam pouco tempo da sua carga horária do curso para a formação nas metodologias de ensino, ou seja, os currículos têm pouco tempo - e espaço - para discutir, experienciar, fruir, criar e expressar poéticas criativas na arte. Isso denota uma formação tênue em artes visuais na formação do pedagogo.

\section{Concluindo}

A análise do conteúdo das 43 pesquisas, publicadas em artigos de periódicos e de anais e em teses e dissertações, permitiu descobrir resultados inacabados, fazer um balanço-síntese do conhecimento produzido, ainda que como resultado parcial, sobre os cursos de Pedagogia e sobre a presença da arte na formação de professores que atuarão na educação infantil e nos anos iniciais. Permitiu identificar o quão pouco este campo é investigado e pesquisado pelos pedagogos, requerendo reflexões emergentes sobre a temática, pois o desenvolvimento e a aprendizagem da arte como conhecimento na formação para a docência é a proposição de uma formação cultural artística com base na experiência estética, na poética, no movimento, na liberdade de expressão e na apreciação. A análise das pesquisas apresenta a preocupação com o campo do conhecimento da arte, rompendo com a visão de atividade e se constituindo como um conhecimento com especificidades que precisam ser estudadas ao longo da 


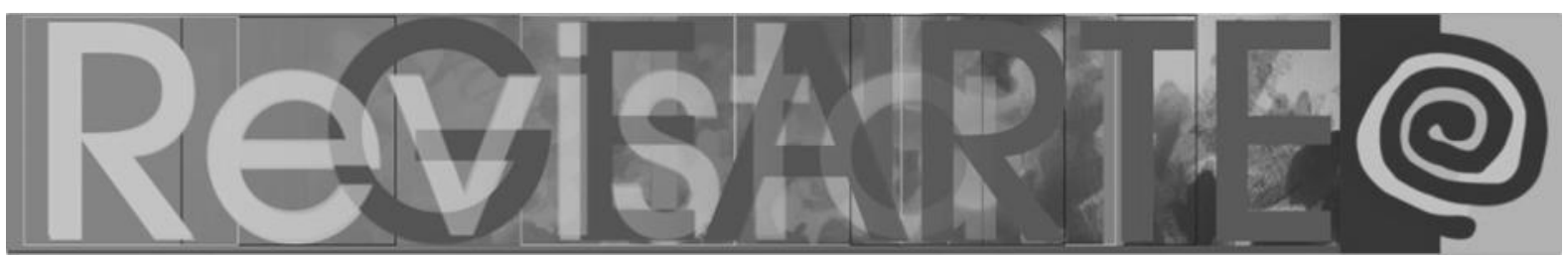

formação. Permitiu, ainda, evidenciar o silêncio quase total em relação ao estudo dos currículos em relação à arte no curso de Pedagogia, que demonstra uma fragilidade nos cursos em realizar uma autorreflexão sobre a própria proposta de formação de professores.

Ademais, permitiu-se verificar que são raras as pesquisas que se preocupam em realizar mapeamento sobre um curso específico, como o mesmo se encontra no decorrer do tempo. Como foi apresentado, o curso de Pedagogia tem crescido ano após ano e, com a abertura tecnológica, os cursos de pedagogia em modalidade EaD tem aumentado consideravelmente. Mais rara ainda nas pesquisas investigadas, é encontrar a organização dos currículos dos cursos de pedagogia em EaD no que diz respeito aos fundamentos da arte - ou à discussão da arte ao longo do processo de formação do pedagogo - nas matrizes curriculares, o que deixa espaço para uma pesquisa futura, visto que é um assunto em aberto.

Por fim e não menos importante, ressaltamos que realizar um mapeamento dos cursos de pedagogia, no Brasil, e do estado da arte e do conhecimento das produções acadêmicas sobre a temática da arte e da pedagogia possibilitou conhecer como está sendo pensada e realizada a formação dos pedagogos em arte no país. Também, possibilitou o conhecimento de uma prévia do entendimento das tendências epistemológicas da Arte na Pedagogia. Para tanto, fomos sustentados pelo desafio e pelo desejo de conhecer o já produzido, para saber o que ainda não foi investigado, assim como, de conhecer as lacunas, os avanços e de dar conta de socializar o produzido, para contribuir e abrir portas, para que, assim, a comunidade acadêmica científica realize outras possibilidades de pesquisa, com novos estudos das artes nos cursos de pedagogia, visando a formação do pedagogo e a sua atuação na formação humana infantil e dos anos iniciais. 


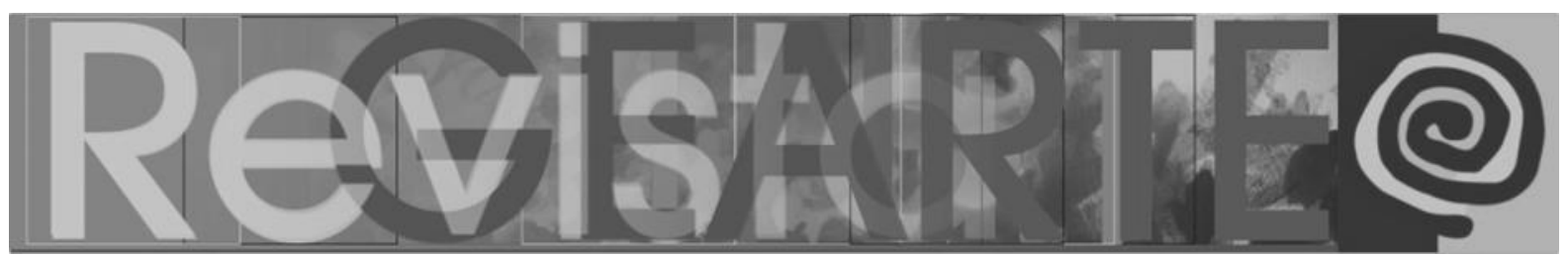

\section{Notas}

1 Nuvem de palavras (Word Cloud) é um gráfico digital que mostra o grau de frequência das palavras em um texto, quanto mais vezes a palavra é usada, mais chamativa é a representação dessa palavra no gráfico.

2 BULATY, Andréia; NUNES, Ana Luiza Ruschel. O currículo e as Artes Visuais nos cursos de licenciatura em Pedagogia no Estado do Paraná. Curitiba: Editora CRV, 2020.

\section{Referências}

ADORNO, Theodor; HORKHEIMER, Max. Dialética do Esclarecimento: fragmentos filosóficos. Rio de Janeiro: Jorge Zahar, 1985.

ADORNO, Theodor. Educação e emancipação. Rio de Janeiro: Paz e Terra, 1995.

ADORNO, Theodor. Teoria da semicultura. Educação e Sociedade, ano 17, n. 56, set./dez. 1996, p. 24-56

ADORNO, Theodor. A dimensão estética. Portugal: Edições 70, 2000.

ADORNO, Theodor. Dialética negativa. Tradução de Marco Antonio Casanova. Rio de Janeiro: Zahar, 2010.

AGUIAR, W. F. Adorno e a dimensão social da arte. Revista Urutágua. Maringá, n. 15, abr./jul. 2018, p. 35-41.

ALVES, Fabiola Cristina. O "estado da arte" do ensino de artes visuais: novos e velhos desafios. Plures humanidades, v. 17, n. 1, 2018, p. 1-12.

ANDRÉ, Marli. Pesquisas sobre formação de professores: uma análise das racionalidades. Educação \& Linguagem, São Paulo, v. 9, n. 14, p. 90-140, jul./dez., 2006.

ARAÚJO, Anna Rita. Os cursos de pedagogia e o ensino da arte: aspectos legais e históricos. Trama Interdisciplinar, São Paulo, v. 6, n. 2, p. 37-58, mai./ago., 2015.

BRASIL, Ministério da Educação. Diretrizes Curriculares Nacionais para o Curso de Graduação em Pedagogia, Licenciatura. Resolução CNE/CP № 1/2006, de 15 de maio de 2006.

BULATY, Andréia; NUNES, Ana Luiza Ruschel. O currículo e as Artes Visuais nos cursos de licenciatura em Pedagogia no Estado do Paraná. 1. ed. Curitiba: CRV, 2020.

BULATY, Andréia; ADENA, Kelly. Ateliê de arte na infância: construção de identidade e sentidos. In: UJIIE, Nájela Tavares; PIETROBON, Sandra Regina Gardacho. Práxis Educativa e Infância: intersecção para a formação integra da criança. Curitiba: CRV, 2017, p. 177- 191.

FERREIRA, Norma Sandra de Almeida. As pesquisas denominadas "Estado da Arte". Educação \& Sociedade, Campinas, v. 23, n. 79, p. 257-272, 2002.

FIGUEIREDO, Sérgio Luiz Ferreira de. A música e as artes na formação do pedagogo: polivalência ou interdisciplinaridade? FAEEBA, Salvador, v. 26, n. 48, p. 79-96, jan./abr. 2017.

FIORENTINI, Dario. Rumos da pesquisa brasileira em educação matemática: o caso da produção científica em cursos de Pós-graduação. Tese (Doutorado em Educação) - Faculdade de Educação, Universidade Estadual de Campinas, Campinas, 1994.

LEITE, Edna Xenofonte et al. A formação do pedagogo para ensino de artes na educação infantil. In: CONGRESSO NACIONAL DE EDUCAÇÃO, 5., 2018, Olinda. Anais [...]. Olinda: CONEDU, 2018, p.10- 30. 


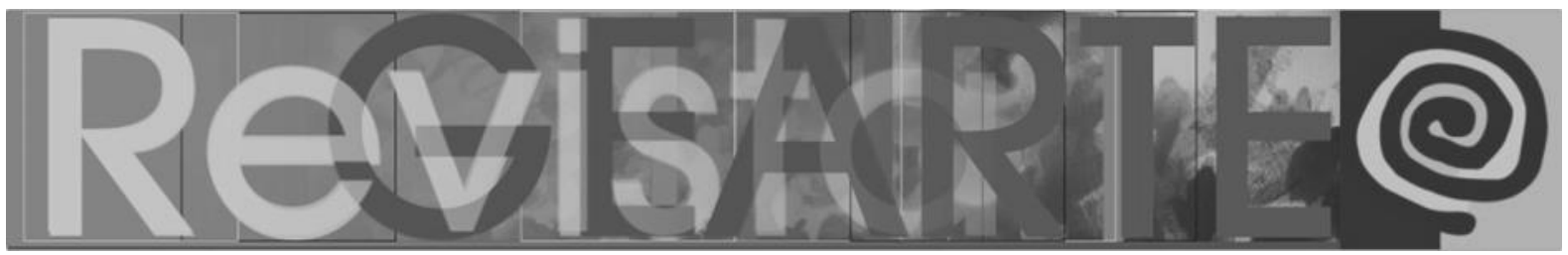

LIBÂNEO, José. O Ensino da Didática, das Metodologias Específicas e dos Conteúdos Específicos do Ensino Fundamental nos Currículos dos Cursos de Pedagogia. Revista Brasileira de Estudos Pedagógicos, Brasília, v. 91, n. 229, p. 562-583, set./dez. 2010.

MARTINS, Mirian Celeste. Artes visuais: "a rainha" das linguagens artísticas nos cursos de pedagogia? Trama Interdisciplinar, São Paulo, v. 6, n. 2, p. 75-92, maio/ago, $2015 a$.

MARTINS, Mirian Celeste; LOMBARDI, Lucia Maria Salgado dos Santos. A arte na pedagogia e a formação do professor para educação infantil e anos iniciais: inquietações e esperanças. Trama Interdisciplinar, São Paulo, v. 6, n. 2, p. 23-36, maio/ago. 2015.

MARTINS, Mirian Celeste. Arte só na aula de arte? Educação, Porto Alegre, v. 34, n. 3, p. 311-316, set./dez. 2015.

MOMOLI, Daniel; EGAS, Olga. A dimensão estética na formação dos pedagogos. Trama Interdisciplinar, São Paulo, v. 6, n. 2, p. 59-74, maio/ago. 2015.

OSTETTO, Luciana Esmeralda; SILVA, Greice Duarte de Brito. Formação docente, Educação Infantil e arte: entre faltas, necessidades e desejos. Educação e Cultura Contemporânea, v. 15, n. 41, p. 260-271, 2018.

PANOFSKY, Erwin. Significado nas Artes Visuais. 3. ed. São Paulo: Perspectiva, 2007.

PIMENTA, Selma Garrido et al. Os cursos de licenciatura em pedagogia: fragilidades na formação inicial do professor polivalente. Educação Pesquisa, São Paulo, v. 43, n. 1, p.15-30, jan./mar. 2017.

ROMANOWSKI, Joana Paulin; ENS, Romilda Teodora. As pesquisas denominadas do tipo "estado da arte" em educação. Diálogo Educacional. Curitiba, v. 6, n. 19, p. 37-50, set./dez. 2006.

ROMERO, Lisane Anes; NUNES, Ana Luiza Ruschel. Formação e atuação de professores em educação infantil: processos colaborativos de pesquisa. 1. ed. Curitiba: Appris, 2017.

SOARES Magda. Alfabetização no Brasil: O Estado do conhecimento. Brasília: INEP/MEC, 1989.

VIDAL, Fabiana Souto Lima. A formação inicial em Pedagogia e o ensino da arte: um estudo em instituições de ensino superior do estado de Pernambuco. Dissertação (Mestrado em Educação) Programa de Pós-Graduação em Educação, Universidade Federal de Pernambuco, Recife, 2011.

ZUIN, Antônio; PUCCI, Bruno; OLIVEIRA, Newton Ramos de. Adorno: o poder educativo do pensamento crítico. 3. ed. Petrópolis: Vozes, 2008.

\section{Ana Luiza Ruschel Nunes}

Professora/pesquisadora Associada e artista. Atua no Curso de Graduação em Artes Visuais, no Programa de Pós-Graduação em Educação, da Universidade Estadual de Ponta Grossa/PR. Graduada em Educação Artística e Artes Plásticas. Mestre em Educação-Universidade Federal de Santa Maria/RS. Doutora em Educação pela Universidade Estadual de Campinas/SP. PósDoutorado em Artes Visuais na Universidade do Estado de Santa Catarina. Coordena o Grupo de Estudos e Pesquisa GEPAVEC-UEPG/CNPQ.

ORCID: https://orcid.org/0000-0001-7338-1615

E-mail: analuizaruschel@gmail.com

Currículo: http://lattes.cnpq.br/2446074749753703

\section{Andréia Bulaty}

Professora do Curso de Pedagogia da Universidade Estadual do Paraná / Campus União da Vitória. Graduada em Pedagogia pela Universidade Estadual do Centro Oeste. Mestre e Doutora em

NUNES, Ana Luiza Ruschel; BULATY, Andréia. Mapeamento dos cursos 624 de Pedagogia e do estado da arte sobre indicadores da Arte na Pedagogia. Revista GEARTE, Porto Alegre, v. 8, n. 2, p. 602-625, maio/ago. 2021.

Disponível em: http://seer.ufrgs.br/gearte 


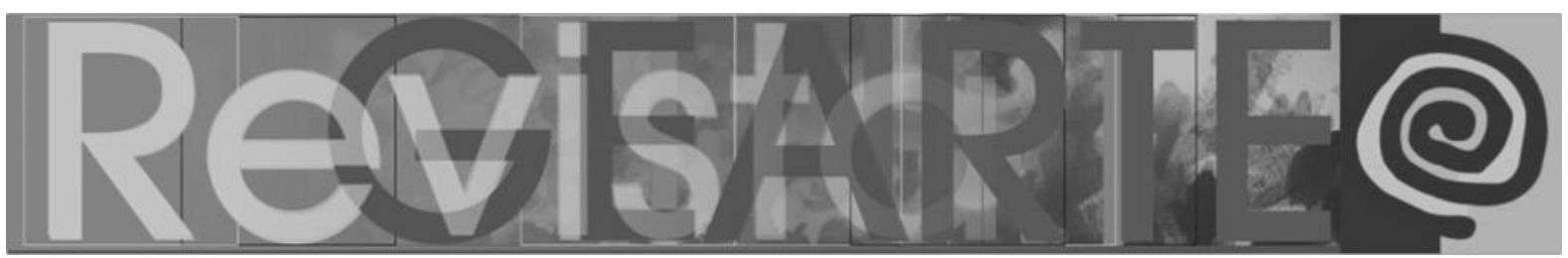

Educação pela Universidade Estadual de Ponta Grossa, onde hoje é pós- doutoranda. Integrante do Grupo de Pesquisa em Artes Visuais, Educação e Cultura; Práxis Educativa: estudos sobre a infância e práticas pedagógicas; Grupo de Estudos e Pesquisa em Educação: Teoria e Prática.

ORCID: https://orcid.org/0000-0001-9974-6221

E-mail: andreiabulat@gmail.com

Currículo: http://lattes.cnpq.br/7885294220537039 